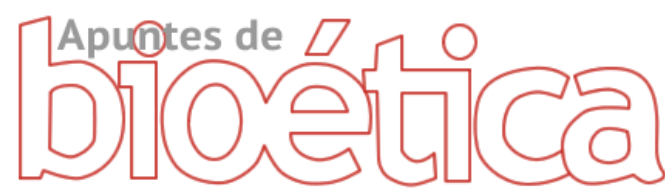

https://doi.org/10.35383/apuntes.v3i1.404

\title{
Un recordatorio biojurídico sobre la vulnerabilidad y la dignidad de los pacientes críticos
}

\author{
Pacheco Leyton A. ${ }^{1}$,
}

\section{INFORMACIÓN DEL ARTÍCULO RESUMEN}

Historia del artículo:

Recibido el 28 de mayo 2020

Aceptado el 31 de julio 2020

Palabras claves:

Personal sanitario,

Dignidad humana,

paciente crítico,

muerte,

derechos,

decisiones.

Hoy en día, la pandemia causada por el COVID-19 nos ha mostrado de manera abrupta una realidad a la que nadie escapa: el misterio de la naturaleza humana que es la muerte. La vida humana no se puede explicar sin la muerte. $Y$ es que el momento de la muerte es tan importante como el del nacimiento porque es parte del proceso natural de la vida. Lo cierto es que la pandemia, trae consigo dolor y sufrimiento previos a la muerte; y es de una letalidad tal que, a pesar de existir grupos de riesgo, todos estamos expuestos al contagio.

La velocidad con la que se propaga el virus y la incapacidad de contener sus efectos ha causado la muerte de millones de personas en todo el mundo, lo que nos lleva a poner la mirada en los lugares donde se enfrenta a la muerte en primera línea. Pero lo más importante es que nos lleva a mirar desde otra perspectiva la fragilidad de la vida.

Los pacientes en estado crítico $^{2}$ (es decir, con severo deterioro en sus funciones orgánicas por enfermedades que, potencialmente pueden complicarse comprometiendo la vida), mantienen intacta su dignidad $y$, al ser un grupo frágil en circunstancias extremas como una pandemia, dejan en evidencia prácticas que vulneran la dignidad de las personas en el ámbito de la actividad asistencial de la salud, por lo que creemos importante recordar desde la mirada biojurídica, la vulnerabilidad de los pacientes en estado crítico.

\section{A biojuridical reminder on the vulnerability and dignity of critical patients}

\section{ABSTRACT}

\section{Keywords.}

Health personnel,

Human dignity,

Critical patient,

Death,

Rights,
Today, the pandemic caused by COVID-19 has abruptly shown us a reality that no one escapes: the mystery of human nature that is death. Human life cannot be explained without death. And it is that the moment of death is as important as that of birth because it is part of the natural process of life.

\footnotetext{
${ }^{1}$ Master en Bioética Universidad de Navarra España, Abogada por la Universidad Católica San Pablo. Docente Universidad Católica de La Plata: La Plata, Buenos Aires Argentina. Email: apachecoleyton@gmail.com ORCID: https://orcid.org/0000-0002-5915-2995

${ }^{2}$ El Dr. Turchetto (2005) define al paciente crítico:

A aquel individuo que, por padecer una enfermedad aguda (...) manifiesta signos y síntomas que, en su conjunto, expresan la máxima respuesta posible de su organismo ante la agresión sufrida. Todo esto en presencia de otro individuo que es capaz de interpretar estas manifestaciones.

Es decir, que los signos y síntomas muestran en todos los órganos y sistemas evaluados, un comportamiento inestable. Los sistemas son: nervioso, central, respiratorio, y cardio-vascular; evalúan también signos en la piel y signos metabólicos (laboratorio).
} 
The truth is that the pandemic brings with it pain and suffering prior to death; and it is of such a lethality that, despite existing risk groups, we are all exposed to contagion.

The speed with which the virus spreads and the inability to contain its effects, has caused the death of millions of people around the world, which leads us to look at the places where death is faced on the front line. . But the most important thing is that it leads us to look at the fragility of life from another perspective.

Critically ill patients (that is, with severe deterioration in their organic functions due to diseases that can potentially be complicated by compromising life), keep their dignity intact and, being a fragile group in extreme circumstances such as a pandemic, leave evidence of that violate the dignity of people in the field of health care activity, for which we believe it is important to remember from a bio-legal perspective, the vulnerability of critically ill patients.

\section{Introducción}

No cabe duda que este año 2020 la sociedad vive convulsionada ante una situación pandémica letal sin precedentes. La necesidad de cuidar y proteger a los más débiles surgió de manera espontánea a causa del sufrimiento $y$, entendimos que la vida es frágil. Tal es así que los gobernantes de todo el mundo debieron tomar decisiones drásticas para intentar paliar las carencias sanitarias que se hicieron evidentes: Hospitales colapsados; personal sanitario escaso, poco preparado, e incluso recibiendo un salario paupérrimo. Por otro lado, falta de educación ciudadana; poblaciones que, en muchas partes del planeta, vive hacinada haciendo imposible cumplir con un distanciamiento social preventivo que tanto recomiendan los médicos infectólogos (Sociedad Argentina de Infectología, 2020). Y sumado a eso, la evidencia de los niveles de corrupción que afectan a nuestra sociedad latinoamericana ya devastada por todo lo antes descrito (Arciniegas Salamanca, 2020).

Todo esto nos lleva a pensar y replantear la centralidad de la persona como único fin de nuestra sociabilidad humana; a buscar el bien común de manera genuina para procurar el bienestar social y, por consiguiente, el bienestar personal tan anhelado; esta vez, desde un contexto en el cuál cualquiera puede ser contagiado de un virus que por el momento no tiene cura y la muerte no es esquiva. Sobre esta cuestión del bien común, la Iglesia Católica en su doctrina social manifiesta que:

Toda sociedad digna de este nombre puede considerarse en la verdad cuando cada uno de sus miembros, gracias a la propia capacidad de conocer el bien, lo busca para sí y para los demás. Es por amor al bien propio y al de los demás que el hombre se une en grupos estables, que tienen como fin la consecución de un bien común. También las diversas sociedades deben entrar en relaciones de solidaridad, de comunicación y de colaboración, al servicio del hombre y del bien común. (Pontificio Consejo Justicia y Paz, 2004).

En otro documento publicado en 1995, en su Carta de los Agentes Sanitarios, expresa que "la actividad médico -sanitaria se funda sobre una relación interpersonal de naturaleza particular. Ella es un encuentro entre una confianza y una conciencia" (Pontificio Consejo para la Pastoral de los Agentes Sanitarios, 1995). Haciendo referencia a que la persona marcada por el sufrimiento y la enfermedad se confía a la 
conciencia de otra persona -siendo éste un agente de la salud- que puede hacerse cargo de su necesidad, y así buscar su bienestar. Sabiendo que el profesional de la salud, no sólo se encuentra preparado para enfrentar la situación de índole médica con sus conocimientos, sino que además, tiene los criterios éticos para tomar decisiones respetando en todo momento la dignidad del paciente.

\section{Resultados, análisis y discusión}

\section{Tratamiento especial a los pacientes críticos}

Al encontrarnos frente a pacientes con severo deterioro de sus funciones orgánicas en uno o varios órganos simultáneamente en estas circunstancias extremas, es cuando debemos volver la mirada compasiva desde la ciencia asistencial hacia el enfermo, depositario de una dignidad inherente cuyos cuidados deberán ser brindados en forma integral. "Esto significa, darle una asistencia que sea la justa a sus necesidades, en la medida prudente y la que corresponda a su realidad clínica" (Passo, 2013, p. 91), buscando siempre la proporcionalidad: sin excesos ni reservas.

Siguiendo la línea de las palabras del doctor Herranz (1999), los enfermos críticos que han sido desahuciados representan un reto para el personal sanitario, porque impone la difícil tarea de preservar su dignidad, evitar daños y prevenir o resolver conflictos que condicionan la responsabilidad de atender a los pacientes al final de la vida; "porque en cierto modo, la salud nos da la capacidad de alcanzar una cierta medida de plenitud humana" (Herranz, 1999). Recordemos que la bioética personalista fundamenta su consideración y respeto en la sustancialidad de la persona mas no en su utilidad o capacidad. Es por ello que para el médico que trata a un paciente con todas las posibilidades de alcanzar salud, no le supone mayor problema reconocer la dignidad de la persona, más aún cuando hay esperanza de desarrollar un proyecto futuro luego de finalizado el tratamiento.

En cambio, en el contexto cultural actual en el cual el dolor y el sufrimiento debe ser desterrado a cualquier costo, lejos de mirar al paciente como una persona digna que sufre una enfermedad que es irreversible $y$, que lo hace transitar una situación de agonía; surge atractiva la idea de la eutanasia, evocada como un derecho que tiene toda persona a una muerte digna, a una muerte sin sufrimiento.

Cuando la sociedad reclama la eutanasia, como huida del dolor y de la agonía, es porque los valores respecto de la vida humana han decaído primero en el espíritu personal y, luego, en la sociedad y el derecho (Sgreccia, 2009). Ya lo decía el neurólogo Viktor Frankl ${ }^{3}$ "vivir significa asumir la responsabilidad de encontrar la respuesta correcta a los problemas que ello plantea y cumplir las tareas que la vida asigna continuamente a cada individuo" (Frankl, 1991, pp. 81-82) incluso cuando el problema sea precisamente la vida antes de morir.

Este eufemismo tan instalado en nuestra sociedad, no ayuda en nada al personal sanitario frente a una situación de enfermedad terminal, dolor y sufrimiento -incluso moral-, sobre todo cuando no existe una retroalimentación en la relación médico paciente, en el cual se informe a la persona sobre su tratamiento, se aclaren dudas, o se mediten consultas con la familia porque las circunstancias del momento lo hacen imposible. El enfermo crítico generalmente está en estado de inconciencia y la responsabilidad de tomar decisiones en situaciones límite recae en el cuerpo médico que deberá actuar en consecuencia, velando por el bienestar de la persona. En este sentido, es importante evitar las medidas extremas y desproporcionadas; aunque decirlo parezca algo sencillo, en la práctica se torna difícil pues, cada acción llevada a cabo

\footnotetext{
${ }^{3}$ Viktor Frankl, Fundador de la Logoterapia: un método terapéutico que propone que la voluntad de sentido es la motivación primaria del ser humano en la recuperación integral del paciente; y del Análisis Existencial: como una técnica terapéutica.
} 
puede devenir en un reduccionismo de la persona que se encuentra en manos de terceros.

Hablar de dignidad humana $y$, más aún, conceptualizarla es amplio y complejo. En una primera instancia, lo más que se podría afirmar de la dignidad es que constituye una sublime modalidad de lo bueno: la excelencia de aquello que está dotado de una categoría superior. En sentido absoluto, el vocablo digno apela a una perfección, a una bondad, a algo que, en cualquier caso, hay que calificar como positivo (Melendo y Millán-Puelles, 1996, pp. 31-32). La expresión dignidad humana, se utiliza para referirse a un algo que hay en el hombre que exige que sea tratado de una forma especial respecto al resto de criaturas con las que nos encontramos (Ramiro García, 2000).

Desde la mirada de la fe, la dignidad humana está inmersa en la dimensión del amor por el vínculo creacional.

El hombre está llamado a una plenitud de vida que va más allá de las dimensiones de su existencia terrena, ya que consiste en la participación de la vida misma de Dios. Lo sublime de esta vocación sobrenatural manifiesta la grandeza y el valor de la vida humana incluso en su fase temporal. (Juan Pablo II, 1995).

Frente a la condición especial e inherente de cada ser humano por simple hecho de serlo desde su concepción hasta su muerte natural, el rol de los profesionales de la salud debe ser la de administrar los cuidados necesarios para procurar su bienestar de acuerdo a los medios que disponen. Por el contrario, nunca será el de evaluar la vida de los pacientes -muchas veces según parámetros ideológicos radicales- que consideran que hay vidas que no merecen atención médica y que por el contrario merecen una muerte compasiva.

En la actividad profesional de la salud, los médicos en particular no pueden ser dejados solos y cargados de responsabilidades insostenibles, ante casos clínicos cada vez más complejos y problemáticos, e incluso en fase experimental cuya relevancia socio- sanitaria cobra mayor interés.

Cuando la salud en el paciente se empieza a deteriorar irreversiblemente y entra en la fase terminal, al sufrimiento físico sobreviene el drama psicológico y espiritual de todo aquello que conlleva el morir y necesita además del acompañamiento profesional, un acompañamiento humano. Es decir, poner un especial cuidado en no olvidar que, a pesar de todo, mantiene intacta su dignidad humana.

\section{Situaciones de vulnerabilidad}

Existen variadas situaciones que comprometen la dignidad del paciente $y$ dependerán mucho del contexto social, cultural y hasta económico. Consideramos que profundizar la complejidad de cada situación debe ser materia para otra investigación, sin embargo, trataremos aquí superficialmente algunos ejemplos que nos ayuden a comprender la problemática en los tratamientos que recibe el paciente cuando se encuentra en estado crítico. Negación de derechos:

Existe una corriente reduccionista que exige que la persona, para ser reconocida como tal y ser titular de derechos, debe tener capacidad de conciencia y elección (Ballesteros y Aparisi, 2004). No alcanza con que la persona esté viva, ya que este es un dato meramente biológico, sino que se le debe atribuir la capacidad de autonomía de la voluntad, por lo que se propone negar la dignidad a los seres humanos que no manifiesten esta capacidad y en consecuencia negarles sus derechos al considerarlos seres inferiores, desposeídos de aquella libertad que los hace incapaces de decidir su propio destino, susceptibles de ser sometidos de acuerdo a intereses de terceros. 
Obstinación terapéutica4:

Considerar que el paciente al encontrarse en estado crítico disminuye su dignidad, lo condiciona a recibir maltratos derivados de la obstinación terapéutica, incluso sabiendo que su estado es irreversible.

Muchas veces por la dificultad en la aceptación del proceso de muerte tanto de los médicos y personal tratantes como de la familia, es que se incurre en este error difícil de advertir que además supone una mala práctica médica y una falta deontológica.

\section{Compasión:}

Partimos también de la premisa de subestimar a la persona, movilizando incluso a la opinión pública para legitimar las decisiones que atentan contra su dignidad, alegando compasión por parte del personal sanitario a cargo del tratamiento. Para evitarle lo que se considera el sufrimiento que provoca la gravedad de la enfermedad o la cercanía del fin de su existencia (Washburn, 2002), es que se le inflige la muerte, sea por acción u omisión.

\section{Abandono:}

Consiste en la falta de atención adecuada a las necesidades del enfermo y su familia. Entre sus motivos destacan la falsa idea de que "ya no hay nada que hacer" y una formación insuficiente en cuidados paliativos, así como el miedo o sensación de fracaso profesional (Gomez Sancho, 2015).

Ser débil era, en la tradición médica cristiana, título suficiente para hacerse acreedor al respeto y a la protección (Herranz, 1991). En

${ }^{4}$ O Encarnizamiento Terapéutico: consistente en la aplicación de los medios médicos que no van a conseguir la recuperación del paciente. Ver en Sanz (1999). Y también en Léxico de bioética (2000). nuestros días, en una sociedad de influencia utilitarista se tiende a restringir la atención médica a las personas cuya esperanza de vida es mínima, por carencias económicas e incluso, abandono por xenofobia.

También ha sido moneda corriente en estos tiempos la falta de espacio en los hospitales, los costosos y escasos equipos de protección personal, lo que llevó a tomar la decisión radical de no atender determinadas emergencias por falta de protocolo.

Asimismo, la masificación en los hospitales ha provocado la despersonalización de la asistencia sanitaria, tendiendo a aislar y dejar sólo al moribundo, provocándole angustia y desesperación por no tener contacto con la familia. Ese continuo desarraigo al que se somete al enfermo dificulta la tarea del personal sanitario que intenta pasar de la simple asistencia técnica a la asistencia humana (Sgreccia, 2009).

Estas cuatro situaciones pueden presentar variantes de acuerdo a la historia de cada paciente. Abordar esta problemática conlleva mirar los hechos desde los dos paradigmas en la Bioética: el de los principios y el de las virtudes; al ser ambos complementarios, el paradigma de los principios regirá en el plano de la ética y la objetividad de la verdad moral y; el paradigma de las virtudes se centrará en el sujeto y en su modo de actuar (Ciccone, 2006).

\section{Los derechos del paciente}

La Organización Mundial de la Salud (1990) decretó los derechos del enfermo terminal de cáncer. Posteriormente, en octubre de 2007 publicó una nueva guía sobre los cuidados paliativos de personas que viven con cáncer avanzado (World Health Organization, 2007), reafirmando la importancia de reconocer en los enfermos terminales, su dignidad humana intrínseca e inalienable. De ambos se desprenden 
los todos los derechos que se aplican a cualquier enfermo, pues los fundamentos derivan de derechos universales.

Mencionaremos a continuación los más relevantes:

- Derecho a ser tratado como un ser humano vivo, hasta el momento de la muerte.

- Derecho de obtener atención de médicos y enfermeras, incluso si los objetivos de curación deben ser cambiados por objetivos de confort.

- Derecho de no morir solo.

- Derecho de ser liberado del dolor.

- Derecho de no ser engañado y a obtener una respuesta honesta a cualquier duda.

- Derecho a recibir ayuda de la familia y para la familia en la aceptación de la muerte.

- Derecho a no sufrir inútilmente.

- Derecho a morir en paz y con dignidad.

- Derecho a que el cuerpo sea respetado después de la muerte.

Desde tiempos remotos, la inquietud por el respeto a la vida del débil frente a las atrocidades cometidas contra ellos, a pesar incluso de su licitud, ha provocado discusiones que han perdurado en el tiempo hasta que, luego de la Segunda Guerra Mundial, con la declaración de los Derechos Humanos un 10 de diciembre de 1948, se exhorta a la sociedad a reconocer y respetar el valor intrínseco y universal que posee toda persona, la Dignidad Humana. De esta manera quedarían garantizados todos los derechos de las personas, haciendo tomar parte a los gobiernos para resguardar celosamente estos derechos proclamados.

Es desde entonces, que la dignidad de la persona humana se convierte en un valor fundamental e imprescindible en el ámbito jurídico para proteger la vida del ser humano sin condicionamientos.

\section{El bien morir: la luz de esperanza}

Desligar el concepto de la muerte digna con el de eutanasia es de carácter imperativo. Hay un consenso en la sociedad respecto a la palabra dignidad como algo bueno porque en ella se reconoce un especial merecimiento (Hoyos, 2005), pero, muchas veces se toma esta palabra con un sentido erróneo para apresurar la muerte del moribundo, o de aquel paciente crítico que sufre.

El personal sanitario debe velar celosamente porque su accionar no se deshumanice a pesar de las dificultades que se presentan. El trabajo que realizan diariamente con sus conocimientos y atenciones acompañando al enfermo que inicia su tránsito a la muerte, es una oportunidad para renovar su vocación de servicio a la sociedad.

La forma genuina de amar la vida es a través de la entrega personal al servicio del otro, Es fundamental que, al adoptar decisiones difíciles respecto a la atención médica para tratar pacientes, no se pierda de vista que se trata de personas humanas, poseedoras de igual dignidad y derechos.

\section{Conclusiones}

Los pacientes en estado crítico en todo momento mantienen intacta su dignidad humana. Para el personal médico y sanitario, no se trata de decidir sobre la vida o sobre la muerte de una persona. Se trata de interrogarse y decidir con conocimiento y ética, sobre el tratamiento y cuidado adecuado, respetando el vivir y morir del enfermo que se le ha confiado. Asimismo, otorgarle un especial cuidado al paciente crítico, garantiza el respeto de sus derechos y facilita los parámetros en la toma de decisiones por parte del personal sanitario evitando, lo más posible, situaciones que 
vulneren la integridad de los pacientes. Estando siempre al servicio de la vida y asistirla hasta final.

\section{Bibliografía}

ARCINIEGAS SALAMANCA, Y. (21 de Junio de 2020). América Latina: la corrupción alcanza niveles alarmantes en medio de la crisis el Covid-19. Obtenido de France24: https://www.france24.com/es/20200620corrupcion-america-latina-covid19coronavirus-malveracion

BALLESTEROS LLOMPART, J., \& APARISI MILLARES, A. (2004). Biotecnología, dignidad y derecho: bases para un diálogo. EUNSA.

CICCONE, L. (2006). Bioética, historia, principios, cuestiones (2da ed.). Ediciones Palabra.

FRANKL, V. (1991). El hombre en busca de sentido (12 ed.). Ed. Herder.

GOMEZ SANCHO, M. (19 de Setiembre de 2015). Atención médica al final de la vida: conceptos $y$ definiciones. Obtenido de Organización Médica Colegial y Sociedad Española de Cuidados Paliativos: http://www.medicosypacientes.com/sites/ default/files/Documento\%20Conceptos\% 20AtencionFinalVida\%202015.pdf

HERRANZ, G. (1991). El respeto médico a la vida terminal. Servei de Documentació Montalegre.

HERRANZ, G. (1999). Ponencia en las Jornadas Internacionales de Bioética "Bioética y dignidad en una sociedad plural". Universidad de Navarra. Pamplon.

HOYOS, I. M. (2005). De la Dignidad y de los Derechos Humanos. Editorial TEMIS.

JUAN PABLO II. (1995). Carta Encíclica, Evangelium Vitae, sobre el Valor y el Carácter Inviolable de la Vida Humana.

Léxico de bioética versión web. (31 de Mayo de 2000). Obtenido https://www.unav.edu/web/unidad-dehumanidades-y-etica-medica/material-debioetica/lexico-de-bioetica

MELENDO, T., \& MILLÁN-PUELLES, L. (1996). Dignidad: ¿Una palabra vacia? EUNSA.

ORGANIZACIÓN MUNDIAL DE LA SALUD. (1990). Alivio del dolor y tratamiento paliativo en cáncer. Informe del comité de expertos. Informes técnicos.

PASSO, E. (2013). Bioética en el aula: cuando nuestros gestos de amor, cuentan. Ediciones Logos.

PONTIFICIO CONSEJO JUSTICIA Y PAZ. (2004). Compendio de Doctrina Social de la Iglesia.

PONTIFICIO CONSEJO PARA LA PASTORAL DE LOS AGENTES SANITARIOS. (1995). Carta de los Agentes Sanitarios. Vaticano.

RAMIRO GARCÍA, F. (2000). Técnicas de Asistencia a la Reproducción Humana, Valoración Ética. Grafite Ediciones.

SANZ, G. (1999). Diccionario Espasa de Medicina. Espasa Calpe.

SGRECCIA, E. (2009). Manual de Bioética I, Fundamentos y Ética Biomédica. Ed BAC.

SOCIEDAD ARGENTINA DE INFECTOLOGÍA. (17 de Junio de 2020). Obtenido de Elementos de Protección Personal en Covid19 Argentina:

https://www.sadi.org.ar/institucional/comi siones-de-trabajo/comision-de-iacs-y-spinf-asoc-al-cuidado-de-la-salud-yseguridad-del-paciente/item/1147-nivelesde-elementos-de-proteccion-personal

TURCHETTO, E. (2005). A qué llamamos paciente críticamente enfermo y cómo lo reconocemos. Revista del Hospital Privado de Comunidad, $8(2)$.

WASHBURN, J. (2002). Compasión y Bioética, Acta Bioethic. año X.

WORLD HEALTH ORGANIZATION. (2007). WHO, Palliative Care: Cancer control. 
Apuntes de bioética Vol. 3. N 1 (2020): 111-118

Knowledge into action. Guide for Effective Programmes. Who Press.

https://www.who.int/cancer/media/FINAL-

de

Palliative\%20Care\%20Module.pdf?ua =1 